\title{
Hepatocyte Nuclear Factor 1-Alpha Hyperinsulinism
}

National Cancer Institute

\section{Source}

National Cancer Institute. Hepatocyte Nuclear Factor 1-Alpha Hyperinsulinism. NCI

Thesaurus. Code C131833.

Hyperinsulinism due to mutation(s) in the gene HNF1A, encoding the transcription factor hepatocyte nuclear factor 1-alpha. This condition may prog ress to diabetes later in life. 